\title{
Variações composicionais de olivinas do complexo alcalino-carbonatítico de Salitre, MG
}

\author{
Elisa Soares Rocha Barbosa ${ }^{1,2,3 *}$, José Affonso Brod ${ }^{1,2,3}$, Pedro Filipe de Oliveira Cordeiro ${ }^{2,3}$, \\ Tereza Cristina Junqueira-Brod ${ }^{1,3}$
}

\begin{abstract}
Resumo O complexo alcalino-carbonatítico-foscorítico de Salitre, pertencente à Província Ígnea do Alto Paranaíba, consiste de três intrusões. Salitre I é composto por bebedouritos, com diques anelares de carbonatitos e foscoritos; Salitre II e III são intrusões menores, dominadas por bebedouritos, e localizadas a norte e a sul de Salitre I, respectivamente. Em Salitre, a olivina ocorre em bebedouritos, foscoritos e carbonatitos, e apresenta teores de forsterita entre 83 e $98 \%$. Rochas menos evoluídas (bebedouritos) contêm olivina com menores teores de forsterita do que rochas mais evoluídas (foscoritos e carbonatitos), sendo que olivinas de carbonatitos são as mais magnesianas do conjunto. Em bebedouritos, a variação no teor de forsterita está relacionada à cristalização fracionada, enquanto nos foscoritos o teor de forsterita aumenta com a diminuição do $\mathrm{MgO}$ na rocha e nos carbonatitos diminui com a diminuição do $\mathrm{MgO}$ na rocha. Variações nas quantidades de $\mathrm{MnO}$ e $\mathrm{CaO}$ podem ocorrer nas olivinas de Salitre, e os controles de sua distribuição ainda não são claros. Por vezes, sugerem variações localizadas na concentração desses elementos no magma em vez de um controle cristaloquímico específico da olivina. Discrepâncias nos teores de $\mathrm{NiO}$ entre olivinas da série bebedourítica e olivinas de foscoritos e carbonatitos podem estar associadas à remoção de Ni do sistema, por cristalização fracionada prévia de olivina rica em Ni a partir de um magma parental silicático, ou, alternativamente, extração de Ni por um líquido sulfetado imiscível.
\end{abstract}

Palavras-chave: Salitre; olivina; bebedouritos; foscoritos; carbonatitos.

\begin{abstract}
Compositional variation of olivines from Salitre alkaline-carbonatite complex, MG. The Salitre alkalinecarbonatite-phoscorite complex belongs to the Alto Paranaíba Igneous Province and consists of three separate bodies. Salitre I is a central, kidney-shaped body composed dominantly of bebedourites, with swarms of ring dykes of carbonatites and phoscorites; Salitre II and III are bebedourite-dominated smaller intrusions, respectively to the north and to the south of Salitre I. Olivine occurs in bebedourites, phoscorites and carbonatites, with forsterite content ranging from 83 to 98 mol. \%. The least evolved rocks (bebedourites) show lower forsterite content than the more evolved members (phoscorites and carbonatittes), and olivine from carbonatites have the highest forsterite content. The compositional range of forsterite content observed in bebedourites is related to crystal fractionation. In phoscorites, forsterite content increases with decreasing whole-rock $\mathrm{MgO}$, and in carbonatites it decreases, with the decreasing whole-rock $\mathrm{MgO}$. Variations in $\mathrm{CaO}$ and $\mathrm{MnO}$ may occur in Salitre olivines. The controls of their distribution are unclear and may suggest local variations in the concentration of these elements in the magma, rather than a crystallographic control of olivine. NiO contents show differences between olivines from bebedourites, and olivines from phoscorites and carbonatites. This discrepancy may be related to the removal of $\mathrm{Ni}$ from the system by early fractionation of Ni-rich olivine from a silicate parental magma or, alternatively, by Ni removal in an immiscible sulfide liquid.
\end{abstract}

Keywords: Salitre; olivine; bebedourites; phoscorites; carbonatites.

INTRODUÇÃO Complexos alcalino-carbonatíticos despertam grande interesse tanto do ponto de vista petrológico quanto metalogenético, mas sua gênese e evolução ainda são objeto de debate, tendo em vista a grande variedade e complexidade dos processos magmáticos envolvidos em sua formação (como cristalização fracionada e/ou imiscibilidade de líquidos). Apesar de o uso de litogeoquímica e geoquímica isotópica ser essencial para o estudo dessas rochas, a química mineral mostra ser uma importante ferramenta que auxilia o entendimento dos processos envolvidos na evolução desses complexos.

A olivina é um mineral relativamente comum em complexos alcalino-carbonatíticos (Eriksson 1989, Gaspar et al. 1998, Chakhmouradian \& Zaitsev 2004, Krasnova et al. 2004a) e costuma ocorrer com maior frequência em rochas das séries silicática (dunitos, wehrlitos, bebedouritos) e foscorítica (foscoritos), enquanto em carbonatitos é uma fase acessória. Por ser um mineral pertencente aos estágios iniciais

\footnotetext{
${ }^{1}$ Grupo de Rochas Alcalinas e Mineralizações Associadas, Universidade Federal de Goiás - UFG, Goiânia (GO), Brasil. E-mails: elisa@iesa.ufg.br, j.a.brod@iesa.ufg.br, tcjbrod@iesa.ufg.br

${ }^{2}$ Programa de Pós-graduação em Geologia, Universidade de Brasília - UnB, Brasília (DF), Brasil. E-mail: cordeiropfo@gmail.com ${ }^{3}$ Conselho Nacional de Desenvolvimento Científico e Tecnológico - CNPq, Brasília (DF), Brasil.

*Autor correspondente
} 
na cristalização de rochas de complexos alcalino-carbonatíticos, é um importante marcador na gênese e evolução dos magmas alcalinos.

O presente trabalho utiliza dados de química mineral de olivinas presentes no complexo alcalino-foscorítico-carbonatítico de Salitre I, Província Ígnea do Alto Paranaíba, para a caracterização das diferentes séries petrogenéticas (bebedourítica, foscorítica e carbonatítica), e investiga os processos petrogenéticos atuantes no complexo.

CONTEXTO GEOLÓGICO As províncias alcalinas das margens da bacia do Paraná resultam de um intenso magmatismo que ocorreu no CentroSul do Brasil e no Paraguai oriental do Eocretáceo ao Eoceno. Tanto o magmatismo na América do Sul (Herz 1977, Toyoda et al. 1994, Gibson et al. 1995a, 1995b, 1997a, Bizzi et al. 1995, VanDecar et al. 1995, Thompson et al. 1998) quanto rochas correlacionáveis na África Ocidental (Milner et al. 1995, Milner \& Le Roex 1996, Lanyon \& Le Roex 1995, Le Roex \& Lanyon 1998) têm sido atribuídos ao impacto de plumas mantélicas na base da litosfera continental.

Segundo esses modelos, o magmatismo do Eocretáceo, incluindo rochas alcalinas e os basaltos do sistema Paraná-Etendeka, está relacionado ao impacto da pluma de Tristão da Cunha (Milner et al. 1995, Milner \& Le Roex 1996, Gibson et al. 1997a, Le Roex \& Lanyon 1998), enquanto o magmatismo do Neocretáceo ao Eoceno que gerou as províncias de Poxoréu, de Goiás, do Alto Paranaíba e da Serra do Mar é atribuído à pluma de Trindade (Crough et al. 1980, Gibson et al. 1995b, 1997b, Thompson et al. 1998). Outros autores contestam o envolvimento de plumas do manto na geração das províncias alcalinas brasileiras, com base na ausência de assinatura geoquímica e/ou isotópica de pluma e na ausência de uma progressão clara de idades ao longo das trajetórias esperadas (Riccomini et al. 2005) ou com base em reconstruções paleomagnéticas (Ernesto 2005).

Nas últimas décadas, diversos estudos geoquímicos, isotópicos e mineralógicos (Woolley 1987, Bizzi et al. 1995, Gibson et al. 1995a, 1995b, 1997a, Morbidelli et al. 1995a, Comin-Chiaramonti \& Gomes 1996, Comin-Chiaramonti et al. 1997, Carlson et al. 1996, Thompson et al. 1998, Brod et al. 2000, 2001, Junqueira-Brod 1998, Junqueira-Brod et al. 2000, 2002, Gomes et al. 1990) foram realizados sobre essas províncias, mas pouca atenção tem sido dada às variações composicionais da olivina em complexos alcalino-carbonatíticos.

As rochas da Província Ígnea do Alto Paranaíba (Fig. 1) incluem kimberlitos, lamproítos e kamafugitos, além de complexos alcalino-carbonatíticos e diques de flogopita picrito (Gibson et al. 1995b). Os dados geocronológicos obtidos por Gibson et al. (1995b) e Sgarbi et al. (2004) indicam um período relativamente restrito de formação da província, entre 80 e $90 \mathrm{Ma}$, a despeito de um intervalo mais amplo registrado na literatura prévia (Ulbrich \& Gomes 1981, Sonoki \& Garda 1988, Bizzi et al. 1993, 1994).

Kamafugitos são amplamente distribuídos e predominam na Província. Ocorrem como inúmeros corpos subvulcânicos de pequenas dimensões e também como lavas e piroclásticas (Grupo Mata da Corda) (Seer \& Moraes 1988, Seer et al. 1989, Sgarbi \& Valença 1993, 1994, Sgarbi \& Gaspar 1995, Gibson et al. 1995a). Lamproítos ocorrem somente na porção NW (Gibson et al. 1995b), e pipes de kimberlito diamantífero (Gonzaga \& Tompkins 1991), contendo xenólitos de granada-lherzolito (Leonardos et al. 1993, Carvalho \& Leonardos 1995), restringem-se ao norte da Província.

A Província Ígnea do Alto Paranaíba contém ainda complexos plutônicos (Fig. 1) compostos de rochas ultramáficas alcalinas, carbonatitos e foscoritos, que intrudem rochas metassedimentares neoproterozoicas dos domínios interno e externo da Faixa Brasília, as quais são tipicamente deformadas em estruturas dômicas por efeito da intrusão. Os complexos compreendem Catalão I e II no sul de Goiás, e Serra Negra, Salitre I, II e III, Araxá e Tapira, no oeste de Minas Gerais (Berbert 1984, Gomes et al. 1990, Morbidelli et al. 1995b, 1997).

O intemperismo tropical predominante na região e os padrões de drenagem centrípeta desenvolvidos a partir de encaixantes mais resistentes (Mariano \& Marchetto 1991, Danni et al. 1991) resultaram em espessa cobertura de solo na maioria dos complexos, favorecendo a concentração econômica do fosfato e nióbio tradicionalmente minerados na região, além de concentrações de titânio, terras raras, barita e vermiculita ainda não aproveitadas comercialmente. Afloramentos são raros, e as melhores amostras para estudos petrográficos e geoquímicos estão restritas a testemunhos de sondagem e, eventualmente, aos pits das minas em operação na área. 


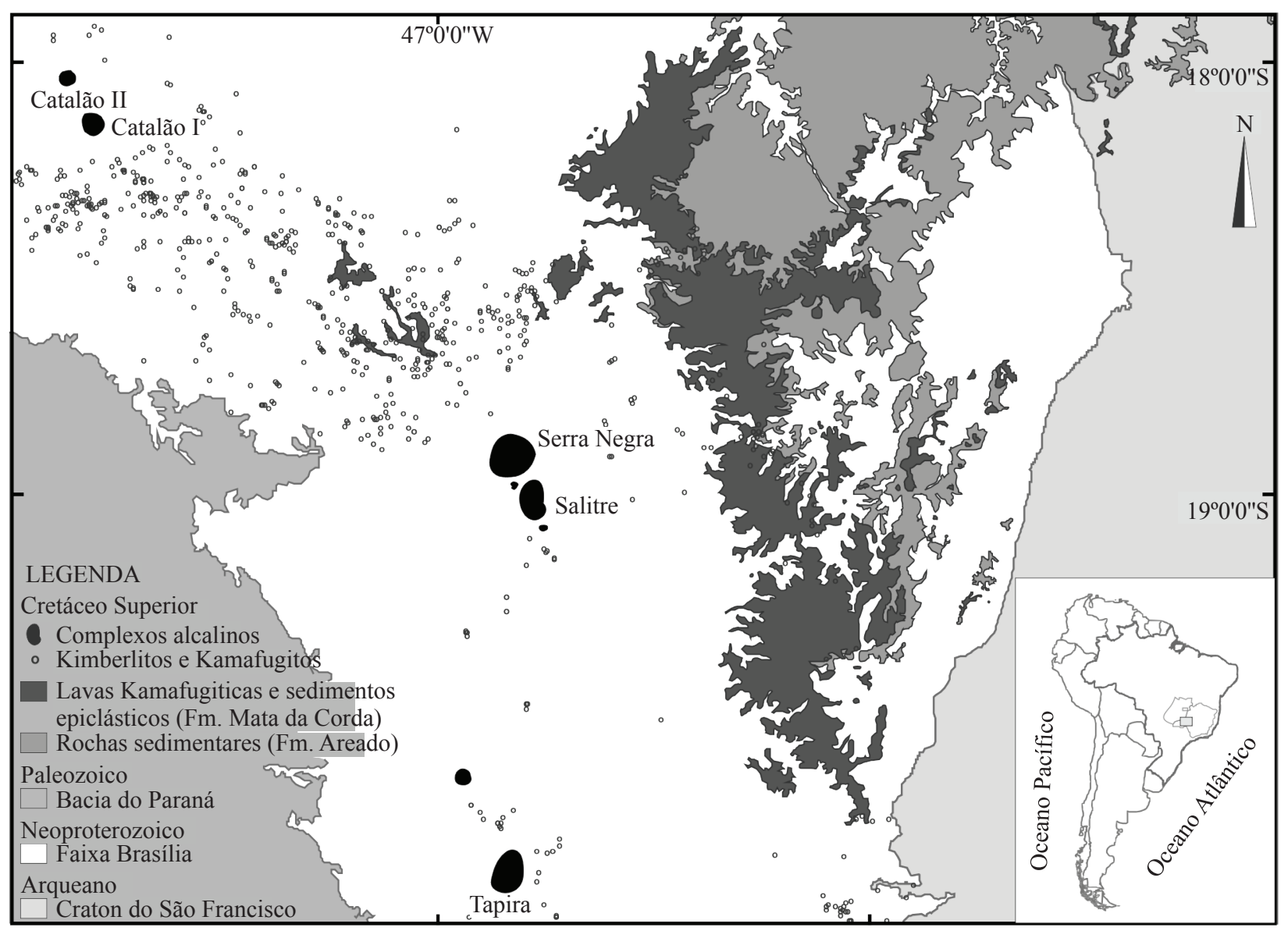

Figura 1 - Mapa geológico da Província Ígnea do Alto Paranaíba (adaptado de Oliveira et al. 2004).

O complexo de Salitre O complexo alcalino-carbonatítico de Salitre é um dos complexos plutônicos da Província Ígnea do Alto Paranaíba e contém como principais litotipos bebedouritos (B1a, B1b, B2) (Barbosa et al. 2012), foscoritos (P1 e P2) e carbonatitos ( $\mathrm{C} 1, \mathrm{C} 2$ e $\mathrm{C} 3)$, descritos a seguir.

As intrusões de Salitre I, II e III (Fig. 2) ocorrem imediatamente a sul do complexo de Serra Negra, na região de Patrocínio, MG. Salitre I possui uma forma oval distorcida, com dimensões aproximadas de $7 \mathrm{~km}$ na direção N-S e $5 \mathrm{~km}$ na direção E-W. Salitre II é um pequeno $\left(2.5 \mathrm{~km}^{2}\right)$ plug localizado entre os complexos de Salitre I e Serra Negra. O corpo de Salitre III foi descoberto recentemente, durante atividades de pesquisa da Fosfértil SA, e forma um pequeno plug a sul de Salitre I. A expressão topográfica de Salitre I e II é menos proeminente que a de Serra Negra, e Salitre III não tem expressão topográfica. Datação K/Ar em flogopita de bebedourito forneceu uma idade de $86.3 \pm 5.7 \mathrm{Ma}$. (Sonoki \& Garda 1988), enquanto Comin-Chiaramonti et al. (2005a) fornecem uma idade de 84 Ma para o complexo. A Serra do Salitre é a localidade tipo da rocha bebedourito, como definida por Tröger (1928).
A Figura 2 mostra um esquema interpretativo da geologia de Salitre I, montado a partir de informações geofísicas (Ribeiro 2008, comunicação pessoal) e da descrição de furos de sondagem. Tendo em vista a grande variabilidade de tipos litológicos, mesmo em escala mesoscópica, as unidades representadas na figura correspondem a zonas de predominância de um determinado tipo litológico em vez de corpos homogêneos. Uma abordagem semelhante foi utilizada com sucesso em mapeamentos de superfície no complexo de Catalão I por Grasso et al. (2006) e Palmieri et al. (2006).

Os tipos petrográficos presentes em Salitre incluem bebedouritos, amplamente dominantes nos três corpos, foscoritos e carbonatitos, além de rochas feldspáticas subordinadas, como tinguaíto e traquito, as quais ocorrem principalmente como diques dentro e fora do complexo. A intrusão de carbonatitos transformou parte das rochas ultramáficas em flogopititos metassomáti$\cos$. Uma auréola parcial de quartzito fenitizado circunda as porções central e sul. Haggerty \& Mariano (1983) e Mariano \& Marchetto (1991) sugerem que parte das rochas feldspáticas na porção sul de Salitre I, previamente interpretadas como traquitos e fonolitos, são na 


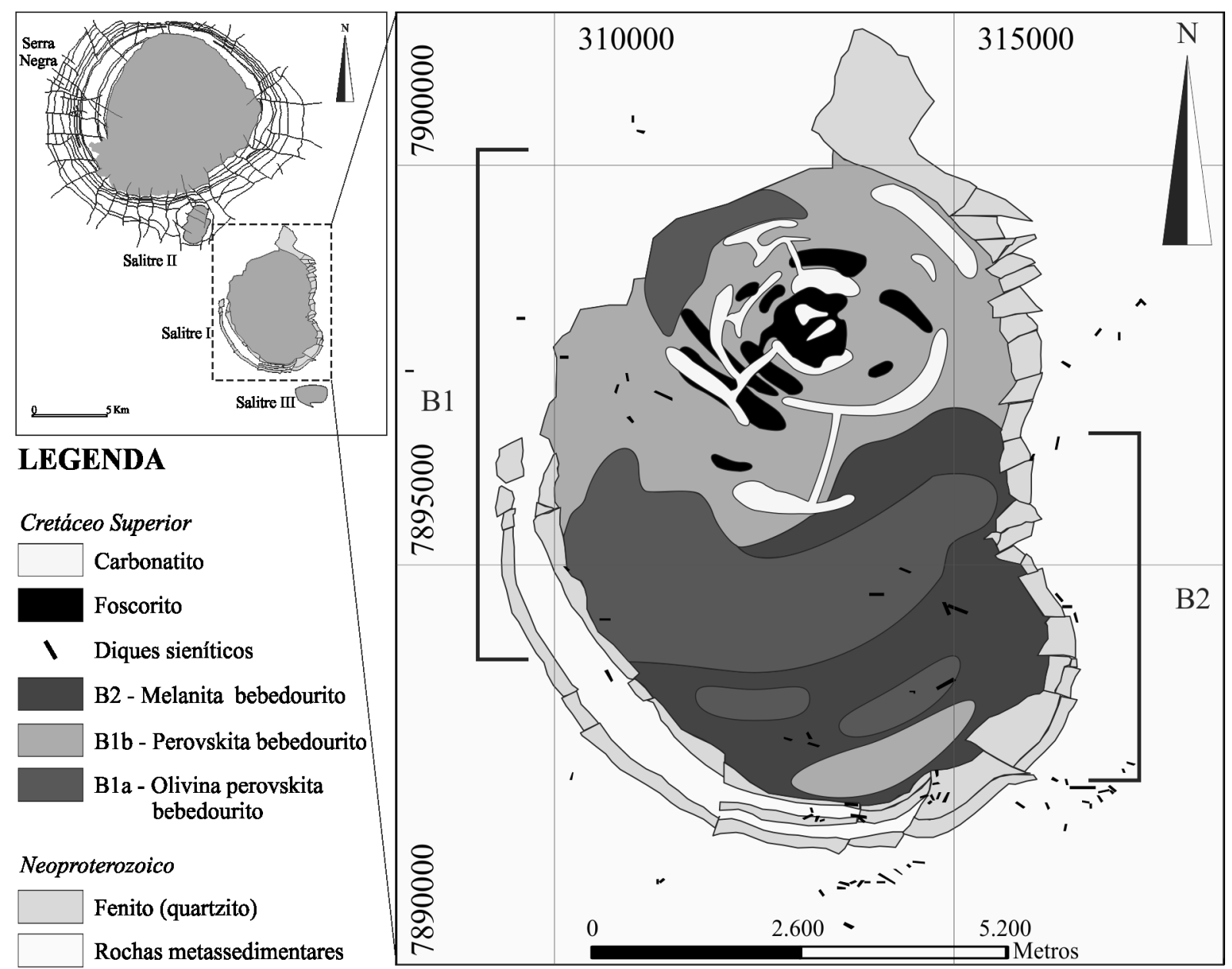

Figura 2 - Esquema geológico do substrato do corpo de Salitre I, com base em informações de campo e testemunhos de sondagem. Adaptado de Barbosa (2009).

verdade aegirina-nefelina-sanidina fenitos reomórficos, os quais se distinguem dos sienitos magmáticos pela ausência de magnetita e presença de plagioclásio sódico, dalyita $\left(\mathrm{K}_{2} \mathrm{ZrSi}_{6} \mathrm{O}_{15}\right)$ e estrôncio-loparita.

No centro-norte de Salitre I e em uma pequena porção ao sul, predominam bebedouritos ricos em perovskita (B1). Dentro desse domínio, no extremo norte e centro-sul, tem-se predominância de uma fácies rica em olivina (B1a), enquanto na porção centro-norte predominam perovskita bebedouritos sem olivina (B1b). A porção sul do complexo é dominada por bebedouritos ricos em melanita, piroxênio e flogopita, mais tardios e que formam uma intrusão independente (B2). Diques de bebedouritos com titanita + melanita e com perovskita + titanita + melanita, relacionados à intrusão B2, ocorrem no interior do domínio B1.

Junto à porção norte, principalmente dentro do domínio dos perovskita bebedouritos, ocorre um sistema de diques anelares interconectados de carbonatitos e foscoritos. Os carbonatitos podem ser dolomíticos ou calcíticos, com presença de olivina, flogopita, magnetita, ilmenita, pirocloro e sulfetos (pirita, pirrotita e calcopirita). Os foscoritos contêm proporções variáveis de olivina, magnetita e apatita (foscoritos, nelsonitos, apatititos e magnetititos), além de flogopita e, como acessórios, pirocloro e sulfetos (pirrotita e calcopirita).

Salitre II é composto principalmente de bebedouritos, localmente recortados por diques e veios de carbonatito, enquanto Salitre III é composto essencialmente por bebedouritos, localmente com foscoritos associados, na porção sul do corpo.

\section{Séries petrogenéticas do complexo de Salitre}

BEBEDOURITOS Variam de finos a grossos, por vezes com aspecto pegmatoide, e são compostos essencialmente de clinopiroxênio ( \pm olivina), flogopita, perovskita, titanita, melanita, magnetita e apatita. Localmente apresentam texturas de acamamento magmático e podem ocorrer como diques. 
Bebedouritos da unidade B1 apresentam variação modal desde rochas com olivina e perovskita (B1a) até perovskita bebedouritos sem olivina (B1b). Bebedouritos com melanita (B2) representam a intrusão de um magma mais evoluído e mais rico em sílica. Nessas rochas, a presença de xenocristais de perovskita envolvidos por sucessivas coroas de titanita e melanita, e a ausência de evidências significativas de assimilação crustal indicam um súbito aumento na atividade de sílica no magma, possivelmente devido à separação de um líquido carbonatítico imiscível. Um estudo detalhado da química mineral, geoquímica de rocha total, isótopos de $\mathrm{Sr}$ e $\mathrm{Nd}$ e petrogênese dos bebedouritos de Salitre é apresentado por Barbosa et al. (2012).

Os diques de sienitos (S1) de Salitre são rochas finas, compostas essencialmente por K-feldspato tabular e aegirina prismática, tendo pequenos cristais de titanita euédrica como principal acessório. Podem apresentar textura traquítica e, por vezes, porfirítica, com fenocristais de piroxênio e K-feldspato de até $1 \mathrm{~cm}$. Representam os termos mais evoluídos da porção silicática do complexo e estão associados aos melanita bebedouritos (B2).

FOSCORITOS A série foscorítica é subordinada no complexo e está restrita à porção norte no domínio dos bebedouritos B1. Os foscoritos estão frequentemente associados a carbonatitos, ou na interface carbonatito-bebedourito. Geralmente são de granulação grossa, compostos por apatita, olivina, flogopita e magnetita. Texturas de movimentação magmática são frequentes.

Os foscoritos de Salitre foram divididos em $\mathrm{P} 1$, compostos por olivina, flogopita aluminosa, apatita, magnetita e relictos de perovskita e P2, constituídos essencialmente de olivina, apatita, magnetita, com pirocloro acessório, e rara flogopita, que grada para tetra-ferriflogopita nas bordas (Barbosa 2009).

\section{CARBONATITOS As rochas desta série variam} de brancas a acinzentadas, finas a grossas. Ocorrem principalmente como diques, com espessura milimétrica (vênulas) a centimétrica. Corpos maiores, de dimensões métricas, observados em testemunhos de sondagem, podem constituir diques mais espessos ou, mais provavelmente, camadas. Vênulas de carbonatito que cortam bebedouritos resultam na formação de flogopititos metassomáticos.
Os diques centimétricos são, em grande maioria, compostos quase exclusivamente por carbonatos, com pouca flogopita e alguns sulfetos (principalmente pirita e pirrotita, subordinadamente calcopirita). Quando em corpos maiores, o carbonatito varia de fino a grosso e frequentemente grada de carbonatito puro a porções mais ricas em magnetita, flogopita, apatita, olivina e pirocloro. Esses minerais podem estar dispersos ou concentrados em bandas, marcando o acamamento magmático. As camadas, possivelmente na forma de uma pasta de cristais (crystal mush) estão frequentemente deformadas e rompidas por movimentações na câmara magmática.

Com base em relações de campo e características petrográficas, foram discriminadas cinco unidades (C1, C2, C3, C3a e D4), em que $\mathrm{C} 1$ e $\mathrm{C} 2$ correspondem a magnesiocarbonatitos, $\mathrm{C} 3$ a calciocarbonatitos, C3a a cumulados nelsoníticos e D4, diques tardios de magnesiocarbonatito.

MATERIAIS E MÉTODOS A área amostrada durante o presente trabalho está restrita à porção norte do corpo principal (Salitre I), onde rochas frescas das séries bebedourítica, foscorítica e carbonatítica estão disponíveis em testemunhos de sondagem. Seções delgadas polidas de cada amostra foram estudadas em luz transmitida e refletida para determinação de composição modal (contagem de pontos) e características texturais. A composição química da olivina foi determinada por WDS usando uma microssonda eletrônica CAMECA SX-50 na Universidade de Brasília (UnB) e uma microssonda eletrônica JEOL JXA 8600 na Universidade de São Paulo (USP). As condições de operação foram de $20 \mathrm{nA}$ e $15 \mathrm{kV}$ para todos os minerais. Para calibração, foi utilizado um conjunto de cristais naturais e sintéticos. Para esse trabalho, foram obtidas 40 análises de olivina em rochas da série bebedourítica, 89 em rochas da série foscorítica e $126 \mathrm{em}$ rochas da série carbonatítica.

OLIVINAS DE SALITRE Em Salitre, a olivina ocorre em bebedouritos, foscoritos e carbonatitos. Em bebedouritos, é uma fase relativamente rara na área de Salitre I estudada neste trabalho, mas é abundante nas porções externas da intrusão B1 e no corpo de Salitre II (Morbidelli et al. 1997). Em foscoritos, a olivina ocorre como fase essencial em todas as unidades (P1 e P2), enquanto entre os grupos de carbonatitos de Salitre apenas dois contêm olivina em quantidades importantes - magnesiocarbonatitos $\mathrm{C} 1$ e calciocarbonatitos $\mathrm{C} 3$. 
Variações texturais de olivinas em Salitre Nas rochas silicáticas, a olivina está restrita aos olivina bebedouritos (unidade B1a) e pode atingir até $50 \%$ da rocha. Ocorre como uma fase cumulus, formando cristais subédricos a anédricos (Fig. 3A) geralmente grossos (1 a $6 \mathrm{~mm})$, e frequentemente apresenta microinclusões de opacos. Localmente, a olivina está envolta por cristais de perovskita (Fig. 3B) ou flogopita (Fig. 3C). Perovskita pode ocorrer na fase cumulus e mais raramente intercumulus, se encontra preservada e frequentemente zonada. Grãos de piroxênio, quando presentes, ocorrem na fase intercumulus, com flogopita, magnetita e rara apatita.

Nos foscoritos de Salitre, a olivina é um constituinte essencial e ocorre nas duas unidades (P1 e P2). Em P1, a variação na proporção da olivina é pequena $(25-34 \%)$, e o mineral ocorre em duas variedades texturais. Uma forma grãos maiores (até $0,5 \mathrm{~cm}$ ), subédricos a anédricos, com inclusões de opacos (provavelmente magnetita), dispostas em um arranjo regular, marcando linhas de crescimento que se tornam mais raras em direção à borda (Figs. 4A e B). Por vezes, encontra-se alterada para clino-humita (Fig. 4C). A outra compreende grãos de até $1 \mathrm{~mm}$, anédricos e com poucas inclusões. Os foscoritos P1 apresentam ainda abundante apatita e flogopita, além de magnetita acessória e relictos de perovskita. Nas amostras de P2, a variação na concentração da olivina é maior (17 - 31\%). Os cristais de olivina estão presentes tanto como fenocristais (2 a $3 \mathrm{~mm}$ ), com apatita, quanto como cristais menores $(0,1$ a $1 \mathrm{~mm})$ subédricos a anédricos em uma matriz fina, com grãos de apatita, magnetita, pirocloro e rara flogopita. Os fenocristais, geralmente bem formados, podem apresentar bordas alteradas e conter inclusões de apatita, além de tipicamente apresentar inclusões fluidas (Figs. 4D e E).
Entre os grupos de carbonatitos de Salitre, apenas dois contêm olivina em quantidades importantes magnesiocarbonatitos $\mathrm{C} 1$ e calciocarbonatitos $\mathrm{C} 3$. Em C1, a olivina é acessória (até 6\%) e está restrita a duas amostras, na forma de cristais anédricos de até $1 \mathrm{~mm}$ (Fig. 5A). A olivina de $\mathrm{C} 3$ apresenta grande variação modal (até 31\%) e textural. Nas rochas deste grupo, a olivina ocorre tanto como grãos menores $(0,1-1 \mathrm{~mm})$ e anédricos quanto como cristais maiores e euédricos (Fig. 5B), e por vezes apresenta zonação (Fig. 5C). Nas raras amostras em que ocorre com pirocloro, a olivina apresenta bordas corroídas (Fig. 5D) e substituição por cristais de flogopita malformados, sugerindo desequilíbrio com o sistema. Pode-se também observar a presença de xenocristais de olivina em calciocarbonatitos $\mathrm{C} 3$, onde a olivina apresenta contornos arredondados (Fig. 5E), sugerindo reabsorção pelo magma.

QUÍMICA MINERAL A composição da olivina é descrita em termos dos membros-finais forsterita (Fo: $\mathrm{Mg}_{2} \mathrm{SiO}_{4}$ ), faialita $\left(\mathrm{Fa}: \mathrm{Fe}_{2} \mathrm{SiO}_{4}\right)$ e tefroíta $\left(\mathrm{Mn}_{2} \mathrm{SiO}_{4}\right)$. Substituição por $\mathrm{Ca}$ resulta na série monticellita $\left(\mathrm{CaMgSiO}_{4}\right)$ - kirschsteinita $\left(\mathrm{CaFeMgSiO}_{4}\right)$, enquanto o membro-final puro kirschsteinita não ocorre naturalmente (Deer et al. 1992). A Tabela mostra análises representativas de olivina de bebedouritos, foscoritos e carbonatitos de Salitre I.

Classificação O intervalo composicional das olivinas de Salitre é relativamente restrito, com composições referentes às faixas da crisolita e forsterita, se considerados todos os tipos de rocha estudados. Apesar dessa pequena variação, o teor de Fo para cada litotipo é bem característico (Fig. 6).

As olivinas de bebedouritos B1a de Salitre I têm composição na faixa da crisolita $\left(\mathrm{Fo}_{83-87}\right)$ (Fig. 6). Esses dados concordam com os obtidos por
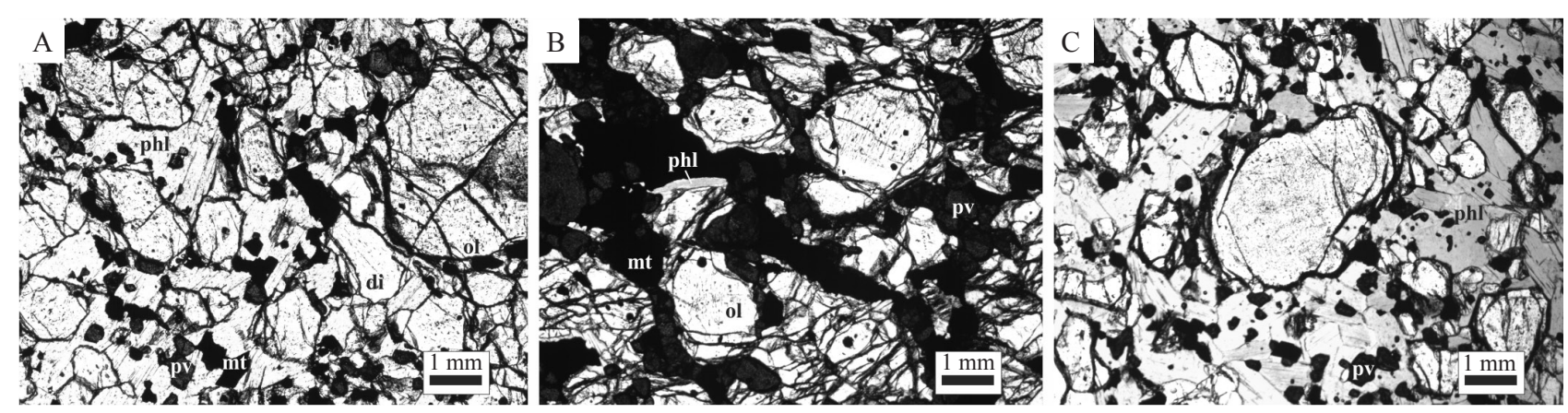

Figura 3 - Aspectos de grãos de olivina em bebedouritos de Salitre I: (A) aspecto geral, com grãos cumulus subédricos a anédricos; (B) olivina envolta por grãos de perovskita; (C) olivina envolta por flogopita. ol: olivina, di: diopsídio, phl: flogopita, pv: perovskita, mt: magnetita. 

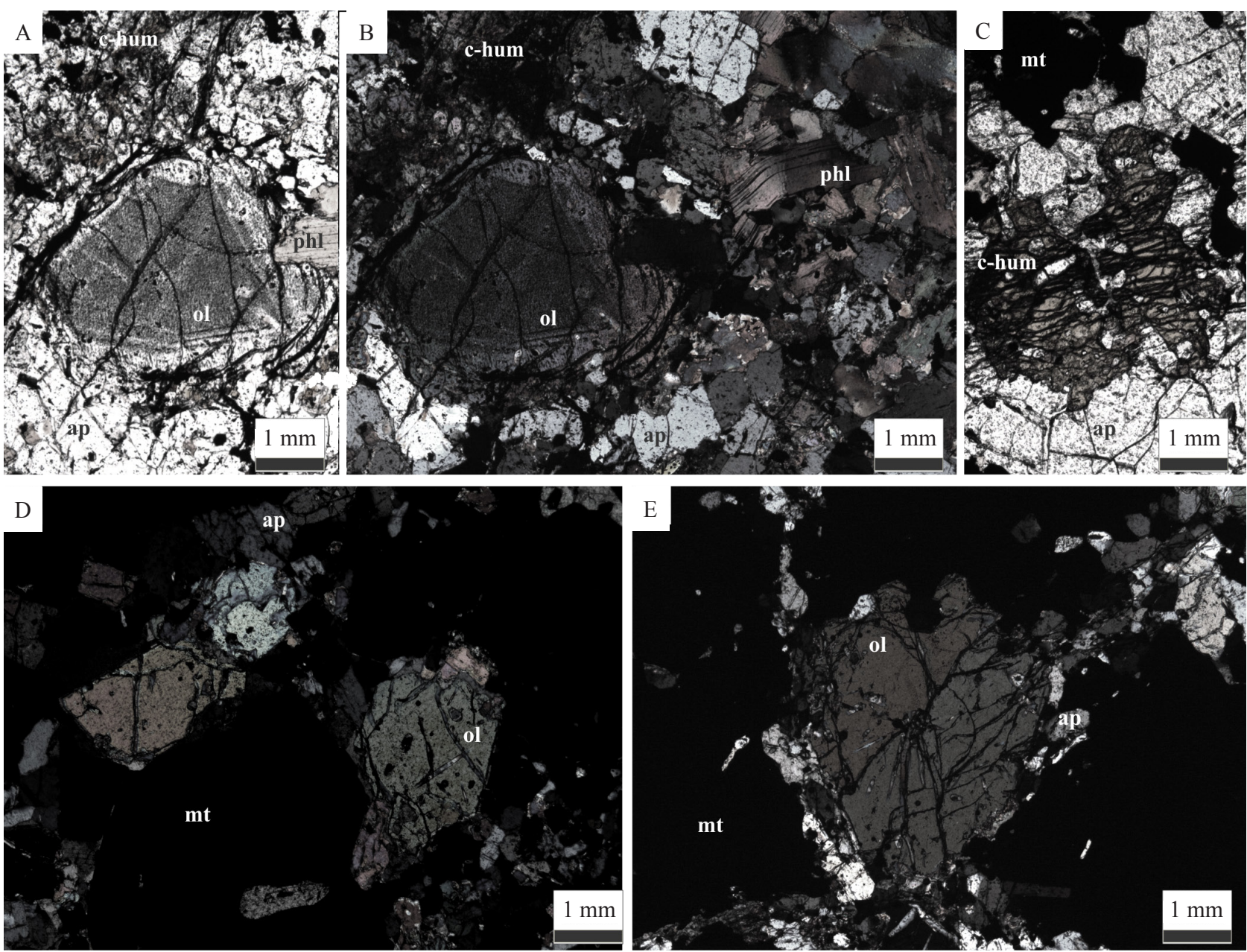

Figura 4-Aspecto geral de olivinas de foscoritos de Salitre I: (A) e (B) inclusões de opacos marcando linhas de crescimento em olivina de P1 (nicois paralelos e cruzados, respectivamente). Notar lamelas de flogopita deformadas devido à movimentação do magma parcialmente cristalizado no canto superior direito de B; (C) pseudomorfo de clinohumita sobre olivina em P1; (D) grãos bem formados de olivina em P2; (E) grão de olivina em P2 com inclusões fluidas em padrão radial. ol: olivina; phl: flogopita; c-hum: clinohumita; ap: apatita; mt: magnetita.

Morbidelli et al. (1997) para olivina em perovskita dunitos e piroxenitos de Salitre II $\left(\mathrm{Fo}_{82-87}\right)$ e também comparáveis com olivinas de rochas similares do complexo de Tapira (APIP), mas levemente menores do que olivinas em flogopita-picritos daquela localidade $\left(\mathrm{Fo}_{84-90}\right.$, Brod 1999) e do complexo de Catalão II na APIP $\left(\mathrm{Fo}_{83,5-89,5}\right.$, Melo 1999).

Em foscoritos, a olivina varia de crisolita a forsterita $\left(\mathrm{Fo}_{87,7-98,9}\right)$ (Fig. 6). Esses valores são substancialmente mais altos do que os observados em olivina das rochas silicáticas ultramáficas (bebedouritos B1a, Barbosa et al. 2012) estudadas. O teor de forsterita comparativamente mais alto em olivinas de foscoritos parece ser característico também em outros complexos alcalinos (Morbidelli et al. 1997, Verhulst 2000, Karchevsky \& Moutte 2004, Krasnova et al. 2004a, Chakhmouradian \& Zaitsev 2004, Lee et al.
2004). Os dados mostram ainda que a olivina de $P 2$ é mais magnesiana $\left(\mathrm{Fo}_{89-98}\right)$ do que a de $\mathrm{P} 1\left(\mathrm{Fo}_{87-93}\right)$, indicando um enriquecimento na molécula de forsterita com a evolução magmática dos foscoritos. Entretanto, dentro de um mesmo grão essa diferença é pequena (menor que $2 \%$ ).

$\mathrm{O}$ intervalo composicional da olivina nos carbonatitos de Salitre é restrito, presente exclusivamente no campo da forsterita $\left(\mathrm{Fo}_{91,0-97,8}\right)$ (Fig. 6). Magnesiocarbonatitos C1 contêm a olivina mais magnesiana $\left(\mathrm{Fo}_{95,5-97,8}\right)$, seguidos de calciocarbonatitos $\mathrm{C} 3\left(\mathrm{Fo}_{91-95,5}\right)$.

Comparando-se os intervalos dos teores de forsterita em olivinas das rochas que ocorrem no complexo de Salitre - bebedouritos B1a, foscoritos P1 e P2 e carbonatitos C1 e C3, nota-se, curiosamente, que as rochas menos evoluídas (bebedouritos) são 

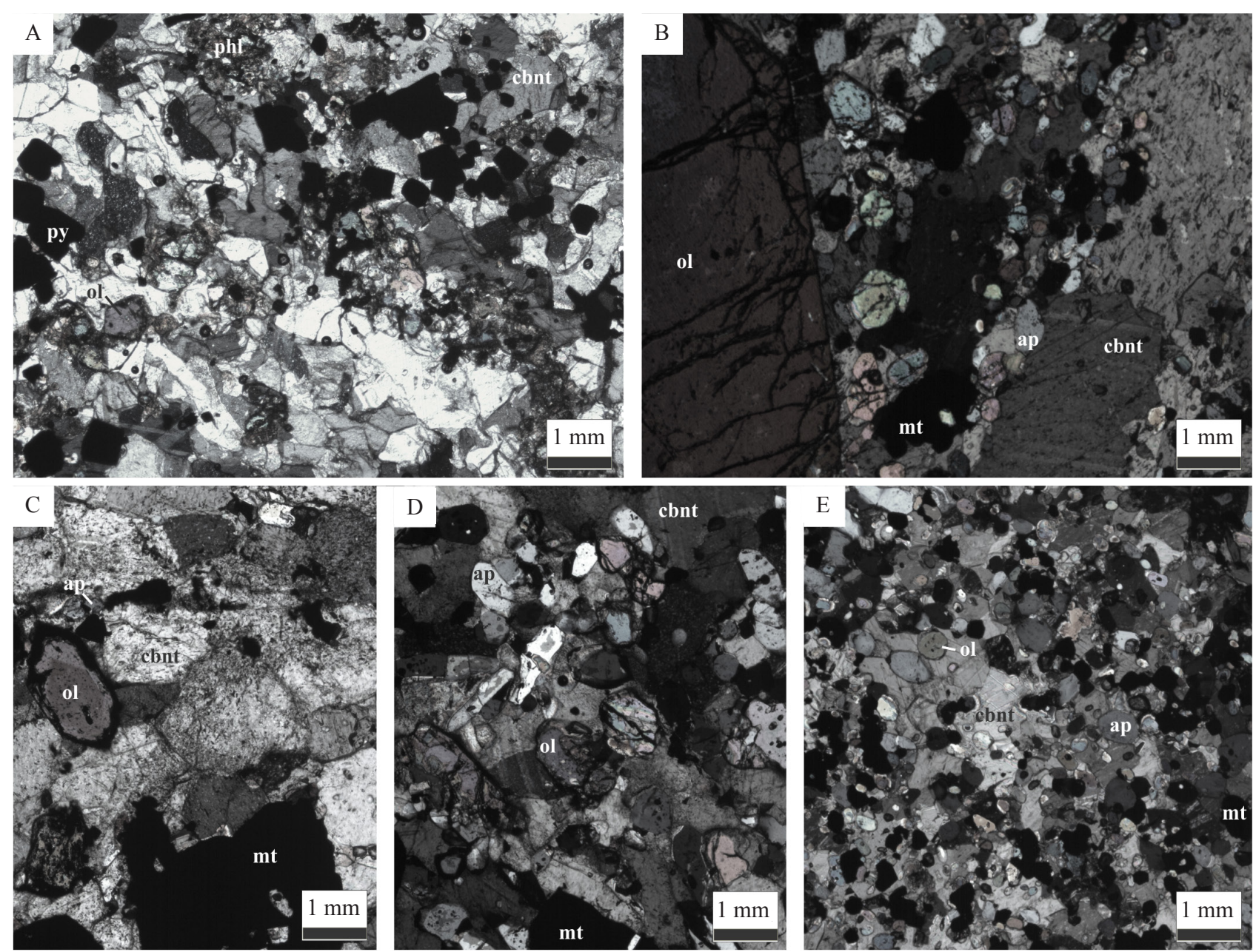

Figura 5 - Aspecto geral de grãos de olivina em carbonatitos de Salitre I: (A) olivina acessória e anédrica em magnesiocarbonatitos $C 1$; (B) grãos de olivina euédricos a anédricos na mesma amostra, mostrando a grande variação textural de olivinas em calciocarbonatitos C3; (C) grão de olivina zonado em C3; (D) grão de olivina com bordas corroídas; (E) grãos de olivina com contornos arredondados, sugerindo reabsorção pelo magma. ol: olivina; py: pirita; phl: flogopita; cbnt: carbonato; ap: apatita.

as que contêm olivina com os menores teores de forsterita. Em rochas mais evoluídas (foscoritos e carbonatitos), o conteúdo de forsterita aumenta, sendo que olivinas de carbonatitos são as mais magnesianas de todo o conjunto. Eriksson (1989) reporta que o teor de forsterita aumenta de foscoritos para carbonatitos em Phalaborwa, e Lee et al. (2004) observam o aumento no teor de forsterita com a evolução dos pares de foscorito-carbonatito de Sokli, mas não discutem as causas para este comportamento.

Em Salitre, a comparação do teor de $\mathrm{MgO}$ na rocha (Barbosa 2009) com a média de $\mathrm{MgO}$ na olivina correspondente (Fig. 7A) sugere que, em olivina bebedouritos B1a, o teor de forsterita diminui com o teor de $\mathrm{MgO}$ na rocha, processo tipicamente relacionado à cristalização fracionada, enquanto nos foscoritos o teor de forsterita aumenta com a diminuição do $\mathrm{MgO}$ na rocha (direção P1-P2), e diminui nos carbonatitos (direção $\mathrm{C} 1-\mathrm{C} 3$ ), com a diminuição do $\mathrm{MgO}$ na rocha.
A despeito das grandes variações no teor de $\mathrm{MgO}$ que ocorrem entre as rochas, a variação entre grãos individuais de olivina na mesma amostra é pequena (menor que $2 \%$ ) e não indica aumento ou diminuição sistemática. Os perfis de análises em um mesmo grão mostram que o teor de forsterita por vezes aumenta e por vezes diminui do centro para a borda do grão (Fig. 7B), sugerindo que o controle do teor de $\mathrm{MgO}$ é mais complexo em foscoritos e carbonatitos, e difere da relação $\mathrm{MgO}-$ rocha/olivina comumente observada em rochas silicáticas. Ainda, pode-se observar um aumento da quantidade de $\mathrm{MgO}$ na olivina com o aumento de $\mathrm{CO}_{2}$ de bebedouritos para foscoritos, relação também observada em carbonatitos, embora com maior dispersão dos dados (Fig. 7C).

Variações composicionais de elementos menores A olivina de bebedouritos $\mathrm{B} 1 \mathrm{a}$ apresenta pequenas quantidades de $\mathrm{MnO}(0,27-0,55 \%) . \mathrm{CaO}$ 
Tabela-Análises de microssonda eletrônica representativas de olivinas de Salitre I

\begin{tabular}{|c|c|c|c|c|c|c|c|c|c|c|c|}
\hline Unidade & B1a & B1a & B1a & B1a & B1a & B1a & $\mathrm{P} 1$ & $\mathrm{P} 1$ & $\mathrm{P} 1$ & P1 & $\mathrm{P} 1$ \\
\hline Análise & UnB & UnB & UnB & UnB & USP & USP & UnB & UnB & UnB & UnB & UnB \\
\hline $\mathrm{SiO}_{2}$ & 40,00 & 40,15 & 40,19 & 40,14 & 39,65 & 39,09 & 41,31 & 40,44 & 39,91 & 40,40 & 41,97 \\
\hline $\mathrm{TiO}_{2}$ & n.d. & 0,07 & 0,03 & 0,05 & n.d. & n.d. & n.d. & 0,10 & n.d. & n.d. & 0,01 \\
\hline $\mathrm{Al}_{2} \mathrm{O}_{3}$ & 0,05 & 0,03 & 0,07 & n.d. & 0,02 & n.d. & n.d. & n.d. & 0,02 & 0,02 & 0,10 \\
\hline $\mathrm{FeO}$ & 12,29 & 13,22 & 13,91 & 14,52 & 12,86 & 13,50 & 6,20 & 9,04 & 11,32 & 9,52 & 5,50 \\
\hline $\mathrm{MnO}$ & 0,37 & 0,47 & 0,43 & 0,55 & 0,36 & 0,39 & 0,72 & 0,71 & 0,90 & 0,92 & 0,62 \\
\hline $\mathrm{MgO}$ & 46,62 & 46,19 & 44,61 & 44,42 & 46,76 & 46,20 & 52,03 & 49,64 & 47,26 & 49,21 & 51,88 \\
\hline $\mathrm{CaO}$ & 0,20 & 0,14 & 0,04 & 0,16 & 0,33 & 0,17 & 0,11 & 0,41 & 0,20 & 0,15 & 0,02 \\
\hline $\mathrm{NiO}$ & 0,07 & 0,03 & 0,26 & 0,11 & 0,20 & 0,21 & n.d. & 0,01 & 0,01 & 0,02 & 0,03 \\
\hline $\mathrm{Cr}_{2} \mathrm{O}_{3}$ & n.d. & n.d. & n.d. & n.d. & 0,01 & n.d. & n.d. & n.d. & n.d. & n.d. & n.d. \\
\hline Total & 99,61 & 100,28 & 99,53 & 99,95 & 100,23 & 99,56 & 100,37 & 100,35 & 99,62 & 100,24 & 100,14 \\
\hline \multicolumn{12}{|c|}{ Cátions calculados com base em 4 oxigênios } \\
\hline $\mathrm{Si}$ & 0,997 & 0,998 & 1,009 & 1,007 & 0,987 & 0,983 & 0,995 & 0,989 & 0,993 & 0,991 & 1,007 \\
\hline $\mathrm{Ti}$ & - & 0,001 & 0,001 & 0,001 & - & - & - & - & 0,001 & 0,001 & 0,003 \\
\hline $\mathrm{Al}$ & 0,002 & 0,001 & 0,002 & - & 0,001 & - & - & 0,002 & - & - & - \\
\hline $\mathrm{Fe}_{2}$ & 0,256 & 0,275 & 0,292 & 0,305 & 0,268 & 0,284 & 0,125 & 0,185 & 0,236 & 0,195 & 0,110 \\
\hline $\mathrm{Mn}$ & 0,008 & 0,010 & 0,009 & 0,012 & 0,008 & 0,008 & 0,015 & 0,015 & 0,019 & 0,019 & 0,013 \\
\hline $\mathrm{Mg}$ & 1,733 & 1,712 & 1,670 & 1,661 & 1,735 & 1,732 & 1,868 & 1,809 & 1,753 & 1,799 & 1,856 \\
\hline $\mathrm{Ca}$ & 0,005 & 0,004 & 0,001 & 0,004 & 0,009 & 0,005 & 0,003 & 0,011 & 0,005 & 0,004 & 0,001 \\
\hline $\mathrm{Ni}$ & 0,001 & 0,001 & 0,005 & 0,002 & 0,004 & 0,004 & - & - & - & - & 0,001 \\
\hline $\mathrm{Cr}$ & & & & & & & - & - & - & - & - \\
\hline Cations & 3,002 & 3,000 & 2,989 & 2,992 & 3,013 & 3,017 & 3,005 & 3,010 & 3,007 & 3,009 & 2,991 \\
\hline $\mathrm{Fa}$ & 0,129 & 0,138 & 0,149 & 0,155 & 0,134 & 0,141 & 0,063 & 0,093 & 0,119 & 0,098 & 0,056 \\
\hline Fo & 0,871 & 0,862 & 0,851 & 0,845 & 0,866 & 0,859 & 0,937 & 0,907 & 0,882 & 0,902 & 0,944 \\
\hline
\end{tabular}

n.d. = não detectado. $\mathrm{Na}_{2} \mathrm{O}$ e $\mathrm{K}_{2} \mathrm{O}$ foram analisados, porém com valores abaixo do limite de detecção.

Tabela-continuação

\begin{tabular}{|c|c|c|c|c|c|c|c|c|c|c|c|c|}
\hline Unidade & $\mathrm{P} 2$ & $\mathrm{P} 2$ & $\mathrm{P} 2$ & $\mathrm{P} 2$ & $\mathrm{P} 2$ & $\mathrm{C} 1$ & $\mathrm{C} 1$ & $\mathrm{C} 3$ & $\mathrm{C} 3$ & $\mathrm{C} 3$ & $\mathrm{C} 3$ & $\mathrm{C} 3$ \\
\hline Análise & UnB & UnB & UnB & UnB & UnB & UnB & UnB & UnB & UnB & UnB & UnB & UnB \\
\hline $\mathrm{SiO}_{2}$ & 42,37 & 41,60 & 41,89 & 41,49 & 41,74 & 42,53 & 41,75 & 40,20 & 41,37 & 41,37 & 41,90 & 42,62 \\
\hline $\mathrm{TiO}_{2}$ & n.d. & 0,02 & n.d. & n.d. & n.d. & 0,01 & 0,03 & n.d. & 0,01 & 0,08 & 0,10 & 0,01 \\
\hline $\mathrm{Al}_{2} \mathrm{O}_{3}$ & 0,02 & 0,02 & 0,01 & 0,03 & n.d. & n.d. & n.d. & 0,01 & 0,01 & n.d. & 0,03 & n.d. \\
\hline $\mathrm{FeO}$ & 4,72 & 3,14 & 5,15 & 6,52 & 5,88 & 4,51 & 2,11 & 8,68 & 6,20 & 7,49 & 7,48 & 2,72 \\
\hline $\mathrm{MnO}$ & 0,64 & 0,45 & 0,75 & 0,74 & 0,86 & 0,43 & 0,35 & 0,89 & 0,53 & 1,12 & 0,96 & 0,42 \\
\hline $\mathrm{MgO}$ & 52,68 & 53,68 & 53,12 & 51,31 & 52,00 & 53,03 & 54,85 & 50,80 & 51,60 & 48,40 & 49,86 & 54,17 \\
\hline $\mathrm{CaO}$ & 0,09 & 0,12 & 0,10 & 0,20 & 0,19 & 0,06 & 0,01 & 0,14 & 0,01 & 1,20 & 0,58 & 0,05 \\
\hline $\mathrm{NiO}$ & 0,03 & n.d. & n.d. & n.d. & 0,04 & 0,01 & n.d. & n.d. & n.d. & 0,05 & n.d. & n.d. \\
\hline $\mathrm{Cr}_{2} \mathrm{O}_{3}$ & n.d. & 0,02 & 0,03 & 0,03 & n.d. & n.d. & n.d. & n.d. & n.d. & n.d. & n.d. & 0,02 \\
\hline Total & 100,55 & 99,04 & 101,02 & 100,32 & 100,71 & 100,58 & 99,11 & 100,73 & 99,75 & 99,71 & 100,93 & 100,00 \\
\hline \multicolumn{13}{|c|}{ Cátions calculados com base em 4 oxigênios } \\
\hline $\mathrm{Si}$ & 1,009 & 1,000 & 0,997 & 1,001 & 1,000 & 1,011 & 0,998 & 0,979 & 1,001 & 1,012 & 1,009 & 1,010 \\
\hline $\mathrm{Ti}$ & - & 0,001 & - & 0,001 & - & & 0,001 & & 0,000 & 0,002 & 0,002 & 0,000 \\
\hline $\mathrm{Al}$ & - & - & - & - & - & & & 0,000 & 0,000 & & 0,001 & \\
\hline $\mathrm{Fe}^{2}$ & 0,094 & 0,063 & 0,103 & 0,132 & 0,118 & 0,090 & 0,042 & 0,177 & 0,125 & 0,153 & 0,151 & 0,054 \\
\hline $\mathrm{Mn}$ & 0,013 & 0,009 & 0,015 & 0,015 & 0,017 & 0,009 & 0,007 & 0,018 & 0,011 & 0,023 & 0,020 & 0,008 \\
\hline $\mathrm{Mg}$ & 1,871 & 1,923 & 1,885 & 1,845 & 1,858 & 1,879 & 1,954 & 1,844 & 1,861 & 1,765 & 1,791 & 1,915 \\
\hline $\mathrm{Ca}$ & 0,002 & 0,003 & 0,002 & 0,005 & 0,005 & 0,002 & 0,000 & 0,004 & 0,000 & 0,031 & 0,015 & 0,001 \\
\hline $\mathrm{Ni}$ & 0,001 & - & - & 0,000 & 0,001 & 0,000 & & & & 0,001 & & \\
\hline $\mathrm{Cr}$ & - & - & 0,001 & 0,001 & - & & & & & & & 0,000 \\
\hline Cations & 2,991 & 2,999 & 3,002 & 2,999 & 3,000 & 2,989 & 3,002 & 3,022 & 2,999 & 2,987 & 2,989 & 2,989 \\
\hline $\mathrm{Fa}$ & 0,048 & 0,032 & 0,052 & 0,067 & 0,060 & 0,046 & 0,021 & 0,088 & 0,063 & 0,080 & 0,078 & 0,027 \\
\hline Fo & 0,952 & 0,968 & 0,948 & 0,934 & 0,940 & 0,955 & 0,979 & 0,913 & 0,937 & 0,920 & 0,922 & 0,973 \\
\hline
\end{tabular}

n.d. = não detectado. $\mathrm{Na}_{2} \mathrm{O}$ e $\mathrm{K}_{2} \mathrm{O}$ foram analisados, porém com valores abaixo do limite de detecção. 


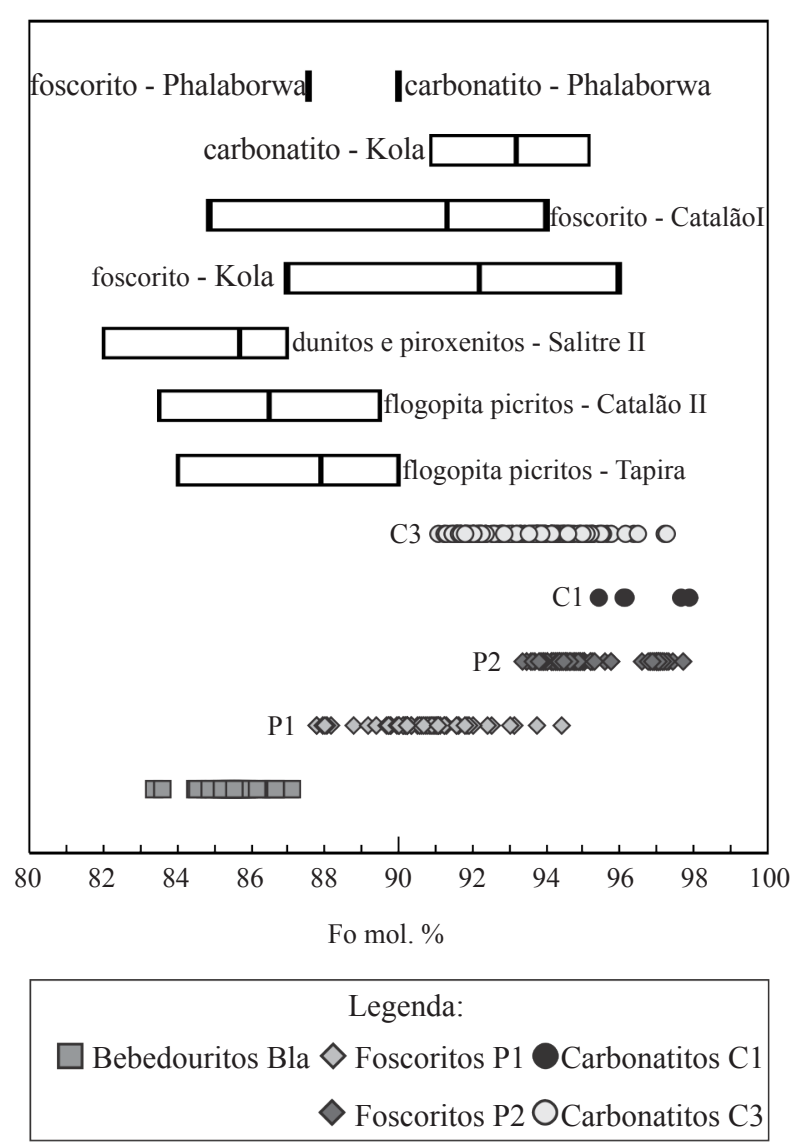

Figura 6 - Variação do teor de forsterita em olivinas nas séries petrogenéticas de Salitre (bebedouritos B1a, foscoritos P1 e P2, e carbonatitos C1 e C3). Campos de olivina e suas respectivas médias dos complexos de Tapira (Brod 1999), Catalão I (Araújo 1996), Catalão II (Melo 1999), Salitre II (Morbidelli et al. 1997) e das províncias de Kola (Verhulst 2000, Karchevsky \& Moutte 2004, Krasnova et al. 2004a, Lee et al. 2004) e Phalaborwa (apenas duas análises) (Eriksson 1989) são mostrados para comparação.

(até $0,36 \%$ ) e $\mathrm{NiO}$ (até $0,26 \%$ ) podem estar presentes, mas não se correlacionam com nenhum outro elemento analisado, nem com o teor de Fo, e os controles para sua distribuição nas olivinas de Salitre ainda não são claros. $\mathrm{Cr}_{2} \mathrm{O}_{3}, \mathrm{~K}_{2} \mathrm{O}$ e $\mathrm{Na}_{2} \mathrm{O}$ estão abaixo do limite de detecção. Brod (1999) e Morbidelli et al. (1997) reportam valores de $\mathrm{CaO}$ suavemente mais altos (até 1,0\%) de bebedouritos ricos em olivina de Tapira e dunitos de Salitre II, respectivamente, para intervalos de NiO similares aos observados aqui. Valores de MnO de Salitre II são parecidos aos de Salitre I, mas as olivinas de Tapira apresentam um teor de $\mathrm{MnO}$ levemente maior (0,53 - 1,02\% de $\mathrm{MnO}$, Brod 1999).

Em foscoritos, os grãos de olivina em P1 são mais ricos em $\mathrm{CaO}$ (até 0,5\%) e ligeiramente mais ricos em $\mathrm{MnO}(0,3$ a $0,9 \%$ ) do que os de P2 (até $0,3 \%$ e
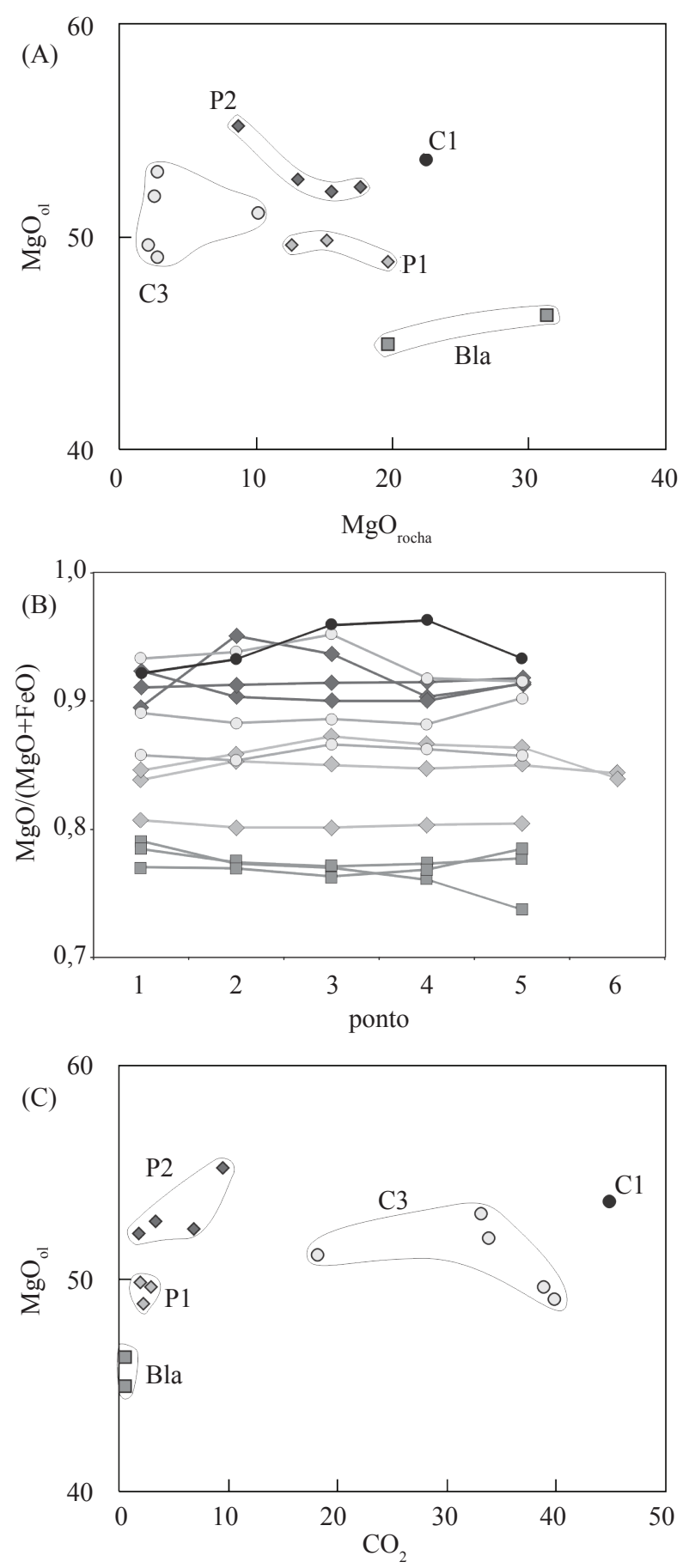

Legenda:

Bebedouritos Bla $\diamond$ Foscoritos P1 Carbonatitos C1

Foscoritos P2 OCarbonatitos C3

Figura 7 - (A) Relação do $\mathrm{MgO}$ na rocha com a média de $\mathrm{MgO}$ na olivina correspondente; (B) variação centro-borda do teor de forsterita em perfis de análises de olivina de bebedouritos Bla, foscoritos P1 e P2 e carbonatitos C1 e C3; (C) relação do $\mathrm{CO}_{2}$ na rocha com a média de $\mathrm{MgO}$ na olivina correspondente. Dados de análise de rocha total extraidos de Barbosa (2009). 
$0,1-0,8 \%$, respectivamente). Considerando-se os dados como um todo, observa-se que $\mathrm{CaO}$ e $\mathrm{MnO}$ diminuem à medida que o conteúdo de forsterita na olivina aumenta de P1 para P2 (Figs. 8A e B). Entretanto, a variação entre centro e borda de um mesmo grão indica que $\mathrm{CaO}$ e $\mathrm{MnO}$ tanto podem aumentar quanto diminuir nas bordas dos grãos de olivina, tanto em P1 quanto em P2. Isso sugere que o controle da entrada de $\mathrm{CaO}$ e $\mathrm{MnO}$ na olivina é mais complexo, provavelmente respondendo mais a variações localizadas na concentração desses elementos no magma do que a um controle cristaloquímico específico da olivina.

A olivina de carbonatitos de Salitre contém baixos teores de $\mathrm{NiO}$ (até $0,09 \%$ ) e $\mathrm{Cr}_{2} \mathrm{O}_{3}$ (até $0,08 \%$ ), além de teores significativos de $\mathrm{TiO}_{2}$ (até $0,4 \%$ ), consistentes com os observados na literatura para olivina de carbonatitos e foscoritos (Eriksson 1989, Gaspar et al. 1998, Krasnova et al. 2004b, Chakhmouradian \& Zaitsev 2004). Uma variação maior ocorre no $\mathrm{CaO}$ e $\mathrm{MnO}$, cujos valores são baixos em olivina de magnesiocarbonatitos $\mathrm{C} 1$ (até $0,06 \%$ de $\mathrm{CaO}$, e $0,3-$ $0,4 \%$ de $\mathrm{MnO}$ ) e altos em olivina de calciocarbonatitos $\mathrm{C} 3$ (até $1,2 \%$ de $\mathrm{CaO}$ e 0,3 a 1,2\% de $\mathrm{MnO}$ ).

Os dados químicos mostram que a diferença nos trends evolutivos permanece em termos de $\mathrm{CaO}$ e $\mathrm{MnO}$, que aumentam com a diminuição da razão $\mathrm{MgO} /$ ( $\mathrm{FeO}+\mathrm{MgO})$, com exceção dos grãos de olivina zonados no calciocarbonatito $\mathrm{C} 3$, que têm o núcleo mais rico em $\mathrm{CaO}$ (Figs. 8A, 8B). Texturalmente, os grãos de olivina dessa rocha estão em equilíbrio com a matriz, sugerindo que essa zonação é uma feição primária. Assim como os altos teores de forsterita podem estar associados com o extremo enriquecimento de $\mathrm{MgO}$ em magnesiocarbonatitos, o núcleo rico em $\mathrm{CaO}$ nesses grãos pode refletir o enriquecimento em $\mathrm{CaO}$ nos calciocarbonatitos antes do início da cristalização de calcita ou, alternativamente, a diferença no teor de $\mathrm{Ca}$ entre o centro e a borda dessas olivinas está refletindo mudanças na composição do magma devido a novas injeções de líquido no sistema.

\section{DISCUSSÃO E CONCLUSÕES A relação} entre $\mathrm{MgO}$ na olivina e $\mathrm{MgO}$ na rocha hospedeira indica que os fatores que controlam o coeficiente de partição de $\mathrm{MgO}$ e $\mathrm{FeO}$ entre olivina e magmas foscoríticos e carbonatíticos são diferentes daqueles atuantes em magmas silicáticos, e que o teor de forsterita na olivina não pode ser usado para comparar rochas silicáticas, foscoríticas e carbonatíticas em termos de evolução magmática. As relações entre Fe
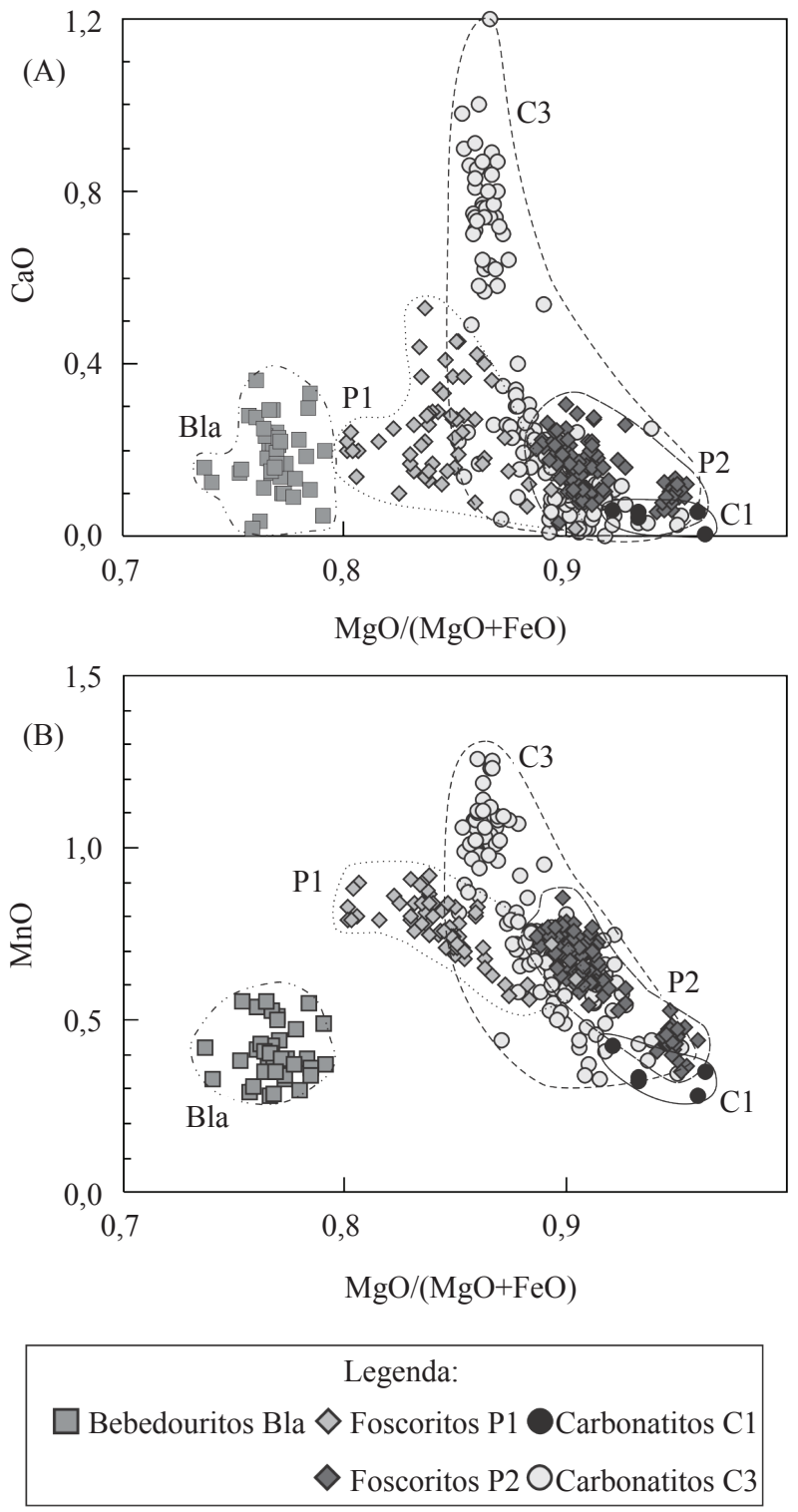

Figura 8 - Relação de $\mathrm{MgO} / \mathrm{FeO}+\mathrm{MgO}$ dos grãos analisados com (A) $\mathrm{CaO}$ e (B) $\mathrm{MnO}$, respectivamente.

e Mg em magmas foscoríticos e carbonatíticos ainda não estão claramente estabelecidas na literatura, mas parece existir uma tendência de enriquecimento em $\mathrm{Mg}$ nos minerais de foscoritos e carbonatitos, respectivamente à sua contraparte silicática, como ilustrado pelas variações composicionais de flogopita (Brod et al. 2001) e magnetita (nossos dados ainda não publicados).

A discrepância no teor de $\mathrm{NiO}$ observado entre olivinas da série bebedourítica e de foscoritos e carbonatitos e suas diferentes relações com o teor de forsterita corroboram os dados de Eriksson (1989), Gaspar et al. (1998), Krasnova et al. (2004a) e Chakhmouradian \& Zaitsev (2004). Esses autores afirmam que o valor insignificante de Ni para alto teor de forsterita é um fator discriminante entre a olivina 

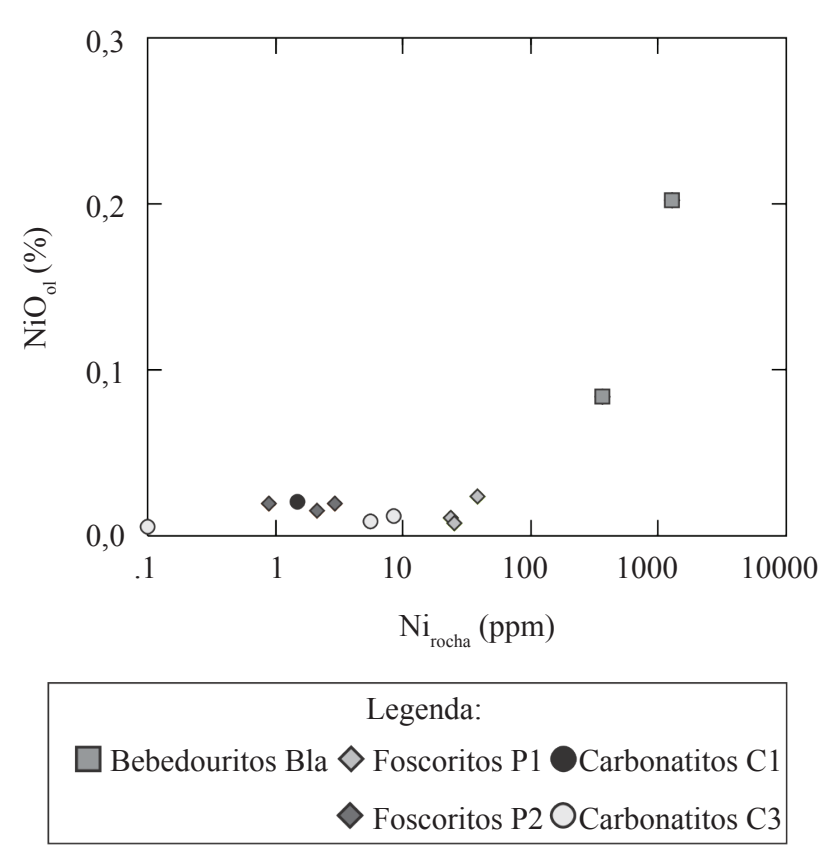

Figura 9-Relação entre o teor de $\mathrm{NiO}(\%)$ em olivina (médias das análises) e teor de Ni (ppm) nas rochas correspondentes de Salitre I (Barbosa 2009). A forte correlação positiva sugere que, ao contrário do $\mathrm{MgO}$, o teor de Ni na olivina é fortemente dependente do teor de Ni disponivel no sistema.

de foscoritos e carbonatitos e a olivina das rochas silicáticas associadas. $\mathrm{O}$ baixo teor de $\mathrm{Ni}$ em foscoritos e carbonatitos pode estar associado à remoção de Ni do sistema, por cristalização fracionada prévia de olivina rica em $\mathrm{Ni}$ a partir de um magma parental silicático. Alternativamente, conforme sugerido por Duke \& Naldrett (1978) para magmas komatiitos, Ni pode ser seletivamente extraído por um líquido sulfetado imiscível.
Em Salitre, sulfetos como pirita, calcopirita e pirrotita ocorrem como acessórios em bebedouritos, foscoritos e carbonatitos, mas não são conhecidas até o momento ocorrências de sulfeto maciço, que seriam esperadas no caso de imiscibilidade de magmas sulfetados, a não ser que estas estejam em grande profundidade. Por outro lado, é possível que o magma que produziu as olivinas analisadas tenha sido previamente empobrecido em $\mathrm{Ni}$ por meio de cristalização fracionada de olivina para formar rochas silicáticas ultramáficas do complexo. O teor de Ni na olivina provavelmente está relacionado com a quantidade de Ni disponível no sistema (Fig. 9). Rochas silicáticas com olivina do complexo chegam a conter 1200 ppm de $\mathrm{Ni}$, e o $\mathrm{NiO}$ presente em grãos de olivina chega até $0,26 \%$. Já em foscoritos, o teor de Ni encontrado nas rochas chega no máximo a $40 \mathrm{ppm}$ para $0,02 \%$ de $\mathrm{NiO}$ na olivina, e em carbonatitos o valor de $\mathrm{Ni}$ nas rochas não ultrapassa 16 ppm para $0,09 \%$ de $\mathrm{NiO}$ na olivina. Naturalmente, essa interpretação só se justifica na premissa de que o magma que gerou foscoritos e carbonatitos seja um produto de evolução a partir de um magma parental silicático e ultramáfico, seja como líquido residual ou por imiscibilidade.

AGRADECIMENTOS Os autores agradecem ao Conselho Nacional de Desenvolvimento Científico e Tecnológico (CNPq) pelas bolsas de pesquisa concedidas. À Fosfertil S.A., pela cessão das amostras e pelo suporte durante o trabalho de campo, e à Universidade de Brasília, pelo suporte laboratorial. Agradecem também ao professor Silvio Vlach e à Universidade de São Paulo pelas análises por microssonda eletrônica.

\section{Referências}

Araújo D.P. 1996. Metasomatismo no complexo carbonatítico Catalão-I: implicações para a composição do magma carbonatítico e para o metasomatismo carbonatítico no manto superior. Dissertação de Mestrado, Instituto de Geociências, Universidade de Brasília, Brasília.

Barbosa E.S.R. 2009. Mineralogia e Petrologia do complexo carbonatítico-foscorítico de Salitre. Tese de Doutorado, Instituto de Geociências, Universidade de Brasília, Brasília, 258 p.

Barbosa E.S.R., Brod J.A., Junqueira-Brod T.C., Dantas E.L., Cordeiro P.F.O., Gomide C.S. 2012. Bebedourite from its type area (Salitre I complex): A key petrogenetic series in the Late-Cretaceous Alto Paranaíba kamafugite-carbonatite-phoscorite association, Central Brazil. Lithos, 144-145: 56-72.
Berbert C.O. 1984. Carbonatites and associated mineral deposits in Brazil. Geological Survey of Japan Report, 263:269-290.

Bizzi L.A., De Wit M.J., Smith C.B., Meyer H.O.A., Armstrong R. 1993. Características isotópicas e origem dos kimberlitos e vulcânicas alcalinas relacionadas em Minas Gerais. In: Simpósio Brasileiro de Geologia do Diamante, 1, Cuiabá, Anais, Universidade Federal do Mato Grasso, Publicação Especial 2/93. p. 141-151.

Bizzi L.A., Smith C.B., Meyer H.O.A., Armstrong R., De Wit M.J. 1994. Mesozoic kimberlites and related rocks in southwestern São Francisco craton, Brazil: a case for local mantle reservoirs and their interaction. In: Meyer H.O.A., Leonardos O.H. (eds.). Proceedings of 5th International Kimberlite Conference, Araxá, CPRM Publ. Esp. 2/91. p. 156-171. 
Bizzi L.A., De Wit M.J., Smith C.B., McDonald I., Armstrong R.A. 1995. Heterogeneous enriched mantle materials and Dupal-type magmatism along the SW margin of the São Francisco Craton, Brazil. Journal of Geodynamics, 20(4):469-491.

Brod J.A. 1999. Petrology and geochemistry of the Tapira alkaline complex, Minas Gerais State, Brazil. PhD Thesis, University of Durham, UK.

Brod J.A., Gibson S.A., Thompson R.N., Junqueira-Brod T.C., Seer H.J., Moraes L.C., Boaventura G.R. 2000. Kamafugite affinity of the Tapira alkaline-carbonatite complex (Minas Gerais, Brazil). Revista Brasileira de Geociências, 30:404-408.

Brod J.A., Gaspar J.C., Araújo D.P., Gibson S.A., Thompson R.N., Junqueira-Brod T.C. 2001. Phlogopite and tetra-ferriphlogopite from Brazilian carbonatite complexes: petrogenetic constraints and implications for mineral-chemistry systematics. Journal of Asian Earth Sciences, 19(3):265-296.

Carlson R.W., Esperança S., Svisero D.P. 1996. Chemical and Os isotopic study of Cretaceous potassic rocks from Southern Brazil. Contributions to Mineralogy and Petrology, 125:393-405.

Carvalho J.B. \& Leonardos O.H. 1995. Preliminary geothermobarometric studies on mantle xenoliths of kimberlites and associated rocks from the Alto Paranaíba, SE Brazil. International Kimberlite Conference, 6, Novosibirsk, Russia, Extended Abstracts. p. 101-103.

Chakhmouradian A. R. \& Zaitsev A. N. 2004. Afrikanda: An association of ultramafic, alkaline and alkali-silicarich carbonatitic rocks from mantle-derived melts. In: F. Wall and A.N. Zaitsev, (eds.) Phoscorites and Carbonatites from Mantle to Mine: the Key Example of the Kola Alkaline Province. Mineralogical Society Series, p. 247-292.

Comin-Chiaramonti P. \& Gomes C.B. 1996. Alkaline magmatism in Central-Eastern Paraguay. Relationships with coeval magmatism in Brazil. São Paulo, EDUSP/ FAPESP, 458 p.

Comin-Chiaramonti P., Cundari A., Piccirillo E.M., Gomes C.B., Castorina F., Censi P., DeMin A., Marzoli A., Speziale S., Velazquez V.F. 1997. Potassic and sodic igneous rocks from eastern Paraguay: their origin from the lithospheric mantle and genetic relationships with the associated Paraná flood tholeiites. Journal of Petrology, 38(4):495-528.

Comin-Chiaramonti P., Gomes C.B., Marques L.S., Censi P., Ruberti E., Antonini P. 2005a. Carbonatites from southeastern Brazil: geochemistry, O-C, Sr-Nd-Pb isotopes and relationships with the magmatism from the Paraná-Angola-Namibia Province. In: CominChiaramonti P., Gomes C.B. (eds.), Mesozoic to Cenozoic alkaline magmatism in the Brazilian Platform. EDUSP/FAPESP, São Paulo, Brazil, p. 657-688.

Crough S.T., Morgan W.J., Hargraves R.B. 1980. Kimberlites: their relation to mantle hotspots. Earth and Planetary Science Letters, 50:260-274.

Danni J.C.M., Baecker M.L., Ribeiro C.C. 1991. The geology of the Catalão I carbonatite complex. In: Leonardos O.H., Meyer H.O.A., Gaspar J.C. (eds), 5th International Kimberlite Conference, Field Guide Book, Araxá, CPRM, Special publication 3/91, p. 25-30.

Deer W.A., Howie R.A., Zussman J. 1992. An introduction to rock-forming minerals. London, Longman, Essex, $696 \mathrm{p}$.

Duke J. M. \& Naldrett A.J. 1978. A numerical model of the fractionation of olivine and molten sulfide from komatiite magma. Earth and Planetary Science Letter, 39:255-266.

Ernesto M. 2005. Paleomagnetism of the post-Paleozoic alkaline magmatism in the Brazilian Platform: questioning the mantle plume model. In: CominChiaramonti P. \& Gomes C.B. (eds.), Mesozoic and Cenozoic alkaline magmatism in the Brazilian Platform, EDUSP/FAPESP, São Paulo, p. 689-705.

Eriksson S.C. 1989. Phalaborwa: A saga of magmatism, metassomatism and miscibility. In: Bell K. (ed.) Carbonatites: genesis and evolution. London, Unwin Hyman, p. 221-254.

Gaspar J. C., Araújo A. L. N., Melo M. V. L. C. 1998. Olivine in carbonatitic and silicate rocks in carbonatite complexes. In: International Kimberlite Conference, 7, Cape Town, Extended Abstracts, 239-241.

Gibson S.A., Thompson R.N., Leonardos O.H., Dickin A.P., Mitchell J.G. 1995a. The Late Cretaceous impact of the Trindade mantle plume: evidence from largevolume, mafic, potassic magmatism in SE Brazil. Journal of Petrology, 36:189-229.

Gibson S.A., Thompson R.N., Dickin A.P., Leonardos O.H. 1995b. High-Ti and low-Ti mafic potassic magmas: Key to plume-lithosphere interactions and continental flood-basalt genesis. Earth and Planetary Science Letters, 136(3-4):149-165.

Gibson S.A., Thompson R.N., Weska R.K., Dickin A.P., Leonardos O.H. 1997a. Late Cretaceous rift-related upwelling and melting of the Trindade starting mantle plume head beneath western Brazil. Contributions to Mineralogy and Petrology, 126:303-314.

Gibson S.A., Thompson R.N., Dickin A.P., Mitchell J.G. 1997b. Temporal variation in magma sources related to the impact of the Tristan mantle plume. In: Hatton C.J. (ed.), PPM'97 International Symposium on Plumes, Plates \& Mineralization, Pretoria, Abstracts, p. 37-38.

Gomes C.B., Ruberti E., Morbidelli L. 1990. Carbonatite complexes from Brazil: a review. Journal of South America Earth Sciences, 3:51-63.

Gonzaga G.M. \& Tompkins L.A. 1991. Geologia do diamante. In: Principais depósitos minerais do Brasil. Brasília, Departamento Nacional de Produção Mineral/Companhia de Pesquisa de Recursos Minerais, 4a, p. 42-58.

Grasso C.B., Ribeiro C.C., Brod J. A., Gaspar J.C. 2006. Mapeamento Geológico de detalhe (1:2000) das frentes de lavra da mina da Fosfertil Fertilizantes Fosfatados S.A. In: Congresso Brasileiro de Geologia, 43, Anais, Aracaju, p. 1-6. CD-ROM.

Haggerty S.E. \& Mariano A.N. 1983. Strontian-loparite and 
strontio-chevkinite: two new minerals in reomorphic fenites from the Paraná Basin carbonatites, South America. Contribution to Mineralogy and Petrology, 84:365-381.

Herz N. 1977. Timing of spreading in the South Atlantic: information from Brazilian alkalic rocks. Geological Society American Bulletin, 88:101-112.

Junqueira-Brod T.C. 1998. Cretaceous alkaline igneous rocks from the Águas Emendadas region, Goiás, Central Brazil. Master of Science Thesis, University of Durham, UK, 161 p.

Junqueira-Brod T.C., Brod J.A., Gibson S.A., Thompson R.N. 2000. Mineral chemistry of kamafugites and related rocks from Águas Emendadas region, Goiás state. Revista Brasileira de Geociências, 30:403-407.

Junqueira-Brod T.C., Roig H.L., Gaspar J.C., Brod J.A., Meneses P.R. 2002. A Província Alcalina de Goiás e a extensão de seu vulcanismo kamafugítico. Revista Brasileira de Geociências, 32:559-566.

Karchevsky P.I. \& Moutte J. 2004. The phoscoritecarbonatite complex of Vuoriyarvi, northern Karelia. In: F. Wall F. \& Zaitsev A.N. (eds.), Phoscorites and Carbonatites from Mantle to Mine: the Key Example of the Kola Alkaline Province. Mineralogical Society Series, p. 163-169.

Krasnova N.I., Petrov T.G., Balaganskaya E.G., Garcia D., Moutte D., Zaitsev A.N., Wall F. 2004a. Introduction to phoscorites: occurrence, composition, nomenclature and petrogenesis. In: Wall F. \& Zaitsev A.N. (eds.), Phoscorites and Carbonatites from Mantle to Mine: the Key Example of the Kola Alkaline Province. Mineralogical Society Series, p. 45-79.

Krasnova N.I., Balaganskaya E.G., Garcia D. 2004b. Kovdor: Classic phoscorites and carbonatites. In: Wall F. \& Zaitsev A.N. (eds.), Phoscorites and Carbonatites from Mantle to Mine: the Key Example of the Kola Alkaline Province. Mineralogical Society Series, p. 99-132.

Lanyon R. \& Le Roex A.P. 1995. Petrology of the alkaline and ultramafic lamprophyres associated with the Okenyenya igneous complex, northwestern Namibia. South African Journal of Geology, 98:140-156.

Le Roex A.P. \& Lanyon R. 1998. Isotope and trace element geochemistry of Cretaceous Damaraland lamprophyres and carbonatites, Northwestern Namibia: evidence for plume-lithosphere interactions. Journal of Petrology, 39:1177-1146.

Lee M.J., Garcia D., Moutte J., Williams C.T., Wall F. 2004. Carbonatites and phoscorites from the Sokli complex, Finland. In: F. Wall and A.N. Zaitsev, (eds.) Phoscorites and Carbonatites from Mantle to Mine: the Key Example of the Kola Alkaline Province. Mineralogical Society Series. p. 133-162.

Leonardos O.H., Carvalho J.B., Tallarico F.H.B., Gibson S.A., Thompson R.N., Meyer H.O.A., Dickin A.P. 1993. O xenólito de granada lherzolito de Três Ranchos 4: uma rocha matriz do diamante na província magmática cretácea do Alto Paranaíba. In: Simpósio de Geologia do Diamante, 1, Anais. Cuiabá, Universidade Federal do Matogrosso, Publicação Especial 2/93, p. 3-16.

Mariano A.N. \& Marchetto M. 1991. Serra Negra and Salitre carbonatite alkaline igneous complex. In: Leonardos O.H., Meyer H.O.A., Gaspar J.C. (eds.). In: 5th International Kimberlite Conference Araxá, Field Guide Book, CPRM, Special Publication 3/91, p. 75-79.

Melo M.V.L.C. 1999. Química dos minerais das rochas do Complexo Carbonatítico de Catalão II: Implicações Petrogenéticas. Dissertação de Mestrado, Universidade de Brasília, Brasília.

Milner S.C., Le Roex A.P., O’Connor J.M. 1995. Age of Mesozoic igneous rocks in northwestern Namibia, and their relationship to continental breakup. Journal of Geological Society (London), 152:97-104.

Milner S.C. \& Le Roex A.P. 1996. Isotope characteristics of the Okenyenya igneous complex, northwestern Namibia: constraints on the composition of the early Tristan plume and the origin of the EM1 mantle component. Earth and Planetary Science Letters, 141:277-291.

Morbidelli L., Gomes C.B., Beccaluva L., Brotzu P., Conte A.M., Ruberti E., Traversa G. 1995a. Mineralogical, petrological and geochemical aspects of alkaline and alkaline-carbonatite associations from Brazil. EarthScience Reviews, 39(3-4):135-168.

Morbidelli L., Beccaluva L., Brotzu P., Conte A.M., Garbarino C., Gomes C.B., Grossi-Sad J.H., Riffel B.F., Ruberti E., Traversa G. 1995b. Aspectos mineralógicos e petrográficos de rochas ultramáficas e carbonatitos do complexo alcalino de Salitre, GO. In: Congresso Brasileiro de Geoquímica, 5, Niterói, Anais, SBGq.

Morbidelli L., Gomes C.B., Beccaluva L., Brotzu P., Garbarino C., Riffel B.F., Ruberti E., Traversa G. 1997. Parental magma characterization of Salitre cumulate rocks (Alto Paranaíba Alkaline Province, Brazil) as inferred from mineralogical, petrographic, and geochemical data. International Geology Review, 39(8):723-743.

Oliveira I.W.B., Sachs L.L.B., Silva V.A., Batista I.H. 2004. Folha SE. 23-Belo Horizonte. In: C. Schobbenhaus, J.H., Gonçalves J.O.S., Santos M.B., Abram R., Leão Neto G.M.M. Matos, R.M. Vidotti, M.A.B. Ramos, J.D.A. Jesus (eds). Carta geológica do Brasil ao milionésimo: Sistema de Informações Geográficas - SIG e 46 folhas na escala 1: 1.000.000. Brasília, CPRM. 41 CD-ROM Pack.

Palmieri M., Ferrari A.J.D., Brod J.A., Barbosa P.A.R. 2006. Geologia da mina de fosfato da Copebrás no Complexo Foscorítico-Carbonatítico de Catalão I. In: Congresso Brasileiro de Geologia, 43, Sociedade Brasileira de Geologia, Aracaju, Anais. CD-ROM.

Riccomini C., Velázques V.F., Gomes C.B. 2005. Tectonic controls on the Mesozoic and Cenozoic alkaline magmatism in the central-southeastern Brazilian Platform. In: Comin-Chiaramonti P., Gomes C.B. (eds.), Mesozoic and Cenozoic alkaline magmatism in the Brazilian Platform. São Paulo, EDUSP/FAPESP, p. 31-55. 
Seer H.J. \& Moraes L.C. 1988. Estudo petrográfico das rochas ígneas alcalinas da região de Lagoa Formosa, MG. Revista Brasileira de Geociências, 18(2): 134-140.

Seer H.J., Moraes L.C.M., Fogaça A.C.C. 1989. Roteiro geológico para a região de Lagoa Formosa-ChumboCarmo do Paranaíba, MG. Boletim Sociedade Brasileira de Geologia, Belo Horizonte, Brazil, 58 p.

Sgarbi P.B.A. \& Valença J.G. 1993. Kalsilite in Brazilian kamafugitic rocks. Minerological Magazine 57: 165-171.

Sgarbi P.B.A. \& Valença J.G. 1994. Mineral and rock chemistry of the Mata da Corda kamafugitic rocks (MG State, Brazil). In: International Symposium on the Physics and Chemistry of the Upper Mantle, São Paulo, Abstracts, CPRM/FAPESP.

Sgarbi P.B.A. \& Gaspar J.C. 1995. Perovskites from the Mata da Corda kamafugites, MG, Brazil. In: International Kimberlite Conference, 6, Novosibirsk, Abstracts, p. 498-499.

Sgarbi P.B.A., Heanman L.M., Gaspar J.C. 2004. U-Pb perovskite ages for brazilian kamafugitic rocks: further support for a temporal link to a mantle plume hotspot track. Journal of South America Earth Sciences, 16(8):715-724.

Sonoki I.K. \& Garda G.M. 1988. Idades K-Ar de rochas alcalinas do Brasil Meridional e Paraguai Oriental: compilação e adaptação as novas constantes de decaimento. Boletim IG-USP, Série Científica, 19: 63-85.

Thompson R.N., Gibson S.A., Mitchell J.G., Dickin A.P., Leonardos O.L., Brod J.A., Greenwood J.C. 1998. Migrating Cretaceous-Eocene magmatism in the Serra do Mar alkaline province, SE Brazil: Melts from the deflected Trindade mantle plume? Journal of Petrology 39:1493-1526.

Toyoda K., Horiuchi H., Tokonami M. 1994. Dupal anomaly of Brazilian carbonatites - geochemical correlations with hotspots in the South-Atlantic and implications for the mantle source. Earth and Planetary Science Lettters, 126:315-331.

Tröger E. 1928. Alkaligesteine aus der Serra do Salitre im westlichen Minas Geraes, Brasilien. Centralblatt für Mineralogie, Geologie und Paläontologie, Abt A: 202-204.

Ulbrich H.H.G.J. \& Gomes C.B. 1981. Alkaline rocks from continental Brazil. Earth-Science Reviews, 17:135-154.

VanDecar J.C., James D.E., Assumpção M. 1995. Seismic evidence for a fossil mantle plume beneath South America and implications for plate driving forces. Nature, 378:25-31.

Verhulst A., Balaganskaya E., Kimarsky Y., Demaiffe D. 2000. Petrological and geochemical (trace elements and $\mathrm{Sr}-\mathrm{Nd}$ isotopes) characteristics of the Paleozoic Kovdor ultramafic, alkaline, and carbonatitic intrusion (Kola Peninsula, NW Russia). Lithos, 51(1): $1-25$.

Woolley A.R. 1987. Alkaline Rocks and Carbonatites of the World. Part 1: North and South America. London, British Museum/University of Texas Press. 216 p.

Manuscrito ID 24668

Recebido em: 13/10/2011

Aprovado em: 13/09/2012 